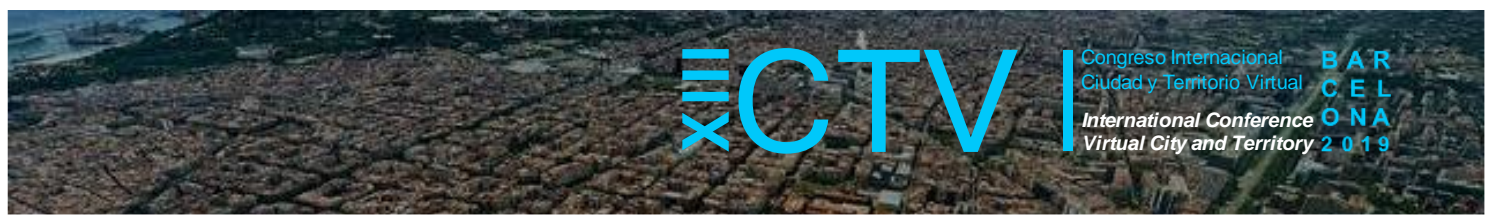

\title{
LA ACTIVIDAD AGRO-EXPORTADORA Y SU RELACIÓN CON EL CRECIMIENTO URBANO DEL VALLE DE ICA - PERÚ
}

Poma, Jorge ${ }^{1 *}$; Garay, Lillian ${ }^{2}$; Romero, Karolina ${ }^{3}$

Remisión inicial: 2019-06-16; Remisión definitiva: 2019-10-21; Publicación: 2019-12-21

Citación: Poma, J. et al. (2019). La actividad agro-exportadora y su relación con el crecimiento urbano del valle de Ica - Perú. En XIII CTV 2019 Proceedings: XIII International Conference on Virtual City and Territory: "Challenges and paradigms of the contemporary city": UPC, Barcelona, October 2-4, 2019. Barcelona:CPSV, 2019, p. 8633.E-ISSN2604-6512.DOI http://dx.doi.org/10.5821/ctv.8633

\section{Resumen}

Los actores, de la actividad agro exportadora en la zona de estudio son fundamentalmente los pequeños agricultores de una parte y los medianos y grandes agricultores de otra parte, estos últimos ligados fuertemente a la actividad agroexportadora. La tierra y el agua son dos recursos preciados para el sostenimiento de la actividad agro-exportadora, actualmente en el mundo existe una tendencia por la concentración de estos preciados recursos y en el caso del valle de Ica esta tendencia no es la excepción.

El objetivo de la comunicación de este trabajo de investigación es conocer el tipo de relación que existe entre la actividad agro-exportadora y el crecimiento rural y urbano del Valle de Ica.

La metodología utilizada para esta investigación es no experimental y descriptiva, la cual consiste en recabar datos estadísticos oficiales los cuales son analizados de manera comparativa y evolutiva, es decir a través el tiempo en dos contextos el nacional y más específicamente en la zona de estudio.

Los datos utilizados son los datos estadísticos de los tres últimos Censos Nacionales Agropecuarios, de donde se analiza la tendencia sobre la propiedad de la tierra, la producción y exportación de productos agrícolas; de otra parte, para analizar la evolución de la extensión agrícola como urbana del Valle de Ica para ello se utiliza los Censo de población y de vivienda, además de fotos satélites tomadas en diferentes lapsos de tiempo para producir un análisis sobre el territorio estudiado y luego hacer la correlación con la actividad agro-exportadora.

Los resultados preliminares demuestran que existe una relación directa con la aparición de los nuevos asentamientos rurales y urbanos en el valle que están estos relacionados directamente a las actividades económicas predominantes en el valle de Ica, haciendo que la ciudad crezca de manera precaria en las en zonas de las periferias de la ciudad sin un planeamiento ordenado. Evidenciándose con ello la existencia de una nueva dinámica de la propiedad de la tierra donde se constata la existencia de la concentración de tierras con fines agro-industriales de parte de los grandes productores agrícolas en desmedro de los pequeños productores. También se constata que existe un crecimiento constante de nuevas tierras agrícolas destinadas al sector agro-industrial exportador, tierras antiguamente eriazas y que en la actualidad han sido ganadas al desierto por medio de una sobre explotación de los recursos acuíferos fósiles, provocando sin duda alguna varios problemas de orden ambiental en este territorio.

El Perú ha experimentado una gran dinámica sobre el mercado de la tierra, como consecuencia de las nuevas políticas económicas del país. Políticas orientadas a la liberalización de los mercados y la promoción de la inversión privada. Y el Boom agro-exportador peruano actual en consecuencia tendría su origen en el cambio de las leyes que regulan la propiedad de la tierra.

Las actividades predominantes en un territorio predeterminan y configuran los nuevos asentamientos urbanos, su aparición sin una planificación representan riesgos urbanos futuros como el crecimiento precario sin servicios básicos y asentándose comúnmente en zonas de alto riesgo frente a fenómenos naturales que cada vez son más frecuentes y violentos en un contexto de cambio climático en un territorio como el peruano.

\footnotetext{
${ }^{1}$ Maestro en Ciencias, Arquitecto y docente Investigador. Universidad Continental; Universidad Nacional de Ingeniería, Facultad de Arquitectura, Urbanismo y Artes; ${ }^{2}$ Universidad Continental, Egresada de la EAP Arquitectura; ${ }^{3}$ Universidad Continental, Egresada de la EAP Arquitectura. * Correo de contacto: jpomag@continental,edu.pe
} 


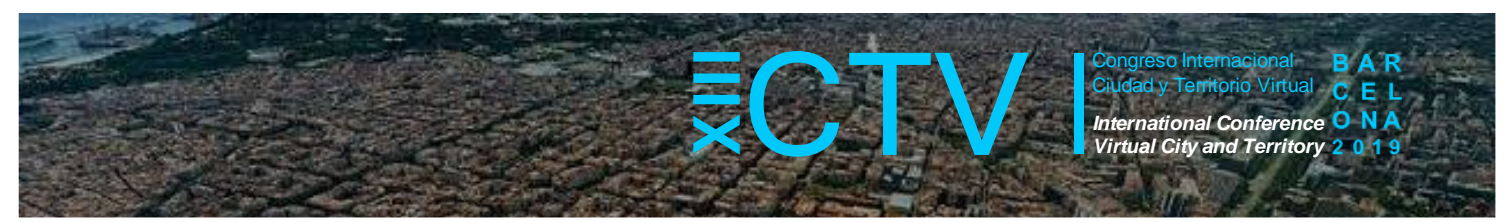

Este trabajo de investigación abre el camino al estudio de la concentración de recursos tan preciados como las tierras agrícolas y el agua. Estudios que deben contar con el enfoque de desarrollo sostenible el cual tiene presente la variable medio ambiental, económica y social. En lo que corresponde al medio ambiental podemos inferir que la concentración de la tierra de parte de los grandes productores agrícolas tiene un impacto negativo en el territorio y sus habitantes, y esto se debería principalmente a los métodos de producción no respetuosos con el medio natural, a la sobreexplotación de aguas subterráneas, a la degradación y contaminación del suelo debido al uso intensivo de productos químicos como pesticidas.

\section{Abstract}

The actors of the agro-export activity in the study area are basically small farmers on one side and medium and large farmers on the other hand, the latter strongly linked to the agro-export activity. Land and water are two precious resources for the support of agro-export activity, there is currently a trend in the world for the concentration of these precious resources and in the case of the Ica Valley this trend is no exception.

The objective of the communication of this research work is to know the type of relationship that exists between the agro-export activity and the rural and urban growth of the Ica Valley.

The methodology used for this research is non-experimental and descriptive, which consists of collecting official statistical data which are analyzed in a comparative and evolutionary way, that is, over time in two contexts the national and more specifically in the study area.

The data used are the statistical data of the last three National Farmers Censuses, from which the trend on land ownership, production and export of agricultural products is analyzed; On the other hand, to analyze the evolution of the agricultural and urban extension of the Ica Valley for this, its use the Population and Housing Census is used, in addition to satellite photos taken at different time periods to produce an analysis of the studied territory and then make the correlation with the agro-export activity.

Preliminary results show that there is a direct relationship with the appearance of the new rural and urban settlements in the valley that are directly related to the predominant economic activities in the Ica Valley, causing the city to grow precariously in areas of the peripheries of the city without an orderly planning. This demonstrates the existence of a new dynamics of land ownership where the existence of the concentration of land for agro-industrial purposes by large agricultural producers at the expense of small producers is confirmed. It is also confirmed that there is a constant growth of new agricultural lands destined for the exporting agro-industrial sector, formerly eriazas lands and that at present have been won to the desert through an over exploitation of fossil aquifer resources, causing without a doubt several environmental problems in this territory.

Peru has experienced a great dynamic on the land market, as a result of the country's new economic policies. Policies aimed at the liberalization of markets and the promotion of private investment. And the current Peruvian agro-exporter Boom would consequently have its origin in changing the laws that regulate land ownership.

The predominant activities in a territory predetermine and shape the new urban settlements, their appearance without planning represents future urban risks such as precarious growth without basic services and commonly settling in highrisk areas in the face of natural phenomena that are increasingly frequent and violent in a context of climate change how in a peruvian territory.

This research work opens the way to the study of the concentration of precious resources such as agricultural land and water. Studies that must have a sustainable development approach which takes into account the environmental, economic and social variable. In what corresponds to the environment we can infer that the concentration of land by large agricultural producers has a negative impact on the territory and its inhabitants, and this is mainly due to production methods that are not respectful of the natural environment, to overexploitation of groundwater, degradation and contamination of the soil due to the intensive use of chemicals such as pesticides.

Palabras Clave: Crecimiento urbano; la actividad agro-exportadora; cambio climático; recursos naturales

Key words: Urban growth; agro-export activity; climate change; natural resources 


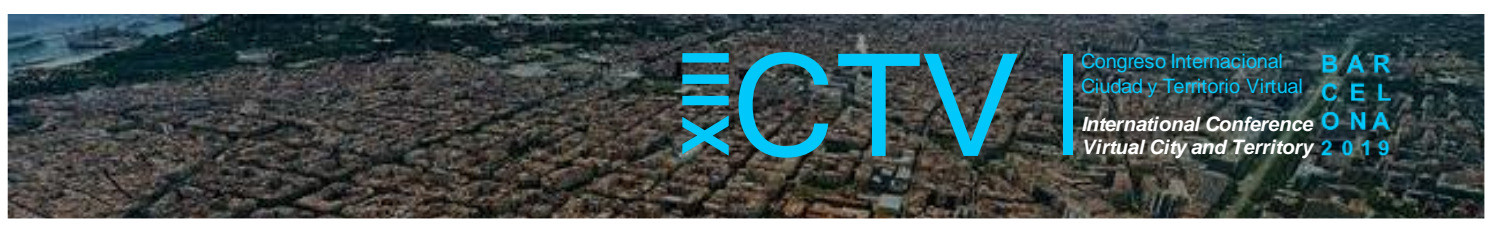

\section{Introducción}

La actividad agrícola en el Perú siempre ha tenido un papel fundamental en el crecimiento y desarrollo de su economía. Ha sido la base económica de las culturas indígenas, preincaicas e incas, en menor medida durante el periodo colonial (1532-1821), y finalmente en su historia reciente en el periodo republicano. La agricultura peruana entonces ha pasado del Ayllu ${ }^{2}$, base económica de la sociedad inca; a la gran propiedad feudal, "Las haciendas", donde la tierra pertenecía al señor feudal y la producción se basaba en trabajo servil; y finalmente ubicándose en una economía capitalista, que actualmente se caracteriza por la presencia de grandes propiedades agrícolas, agro-exportadoras.

\subsection{Superficie agrícola y de pastoreo}

Perú tiene un área de 1,28 millones de km2, lo que representa 128,5 millones de hectáreas, el país tiene una superficie de 38.7 millones de hectáreas para sus actividades agro-pastorales. Perú es el tercer país más grande de Sudamérica, detrás de Brasil y Argentina, pero solo tiene 7 millones de hectáreas para desarrollar la actividad agrícola, "lo que representa el 5.5\% territorio nacional y $18 \%$ del área agro-pastoral"3. Y en la zona de estudio la provincia de Ica se extiende sobre 782 mil hectáreas; 278,6 mil hectáreas para sus actividades agro-pastorales y 126,9 mil hectáreas de superficie agrícola en el 2012. (Ver Figura 1).

\section{Figura 1.Superficie agro-pastoral a nivel nacional y de la provincia de Ica}
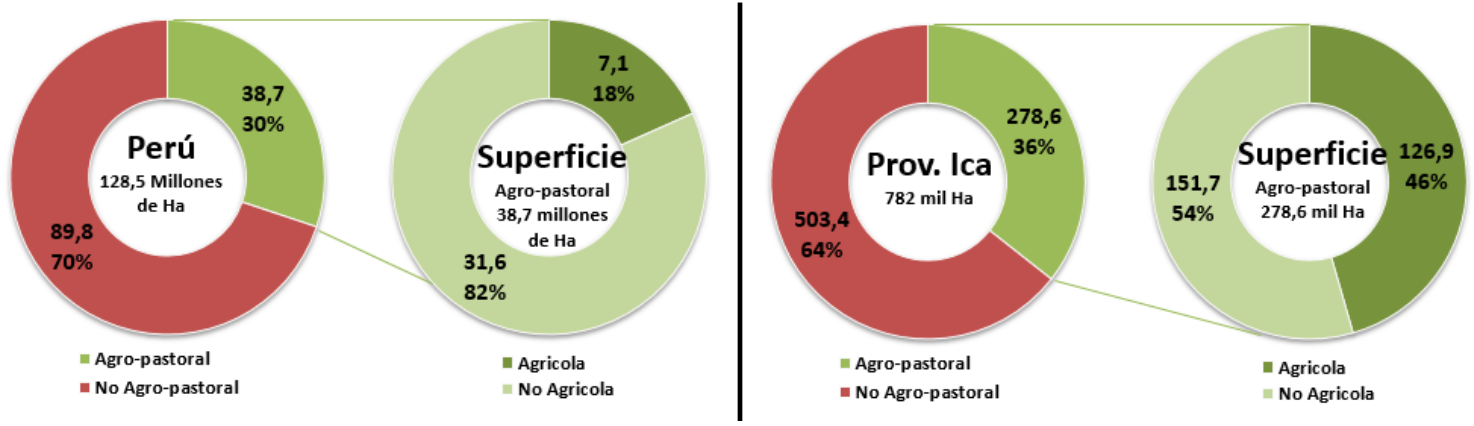

Fuente: INEI, IV censo agrícola 2012. [elaboración propia]

\subsection{Evolución de la superficie y de las unidades agro-pastorales 1961-2012}

A nivel nacional la evolución del número de unidades agro-pastorales (UA) desde 1961 hasta el último censo 2012 muestra un aumento del 162\% de UA, lo que representa un aumento de 1,4 millones de UA en 51 años. Y con respecto la superficie agro-pastoral, en el mismo periodo se muestra un aumento del $154 \%$ de esta área, que pasó de 17,7 millones a 38,7 millones de hectáreas en el mismo período como se aprecia en la Figura 2.

\footnotetext{
2 Según Poma de Ayala (1936), De la Vega (1960) y Murra (1978) Ayllu era una comunidad compuesta por varias familias que trabajaban juntas en tierras pertenecientes a la comunidad. Los miembros de Ayllu trabajaban en su tierra, pero también tenían la obligación de trabajar la tierra del estado. La producción de estas tierras sirvió para alimentar a los nobles y al ejército. Gracias a su régimen colectivista, los incas valorizaron su territorio mediante la construcción de carreteras, sistemas de riego, etc.

${ }^{3}$ Estimaciones realizadas en base a los datos del IV CENAGRO, IV Censo Agrícola en el 2012
} 


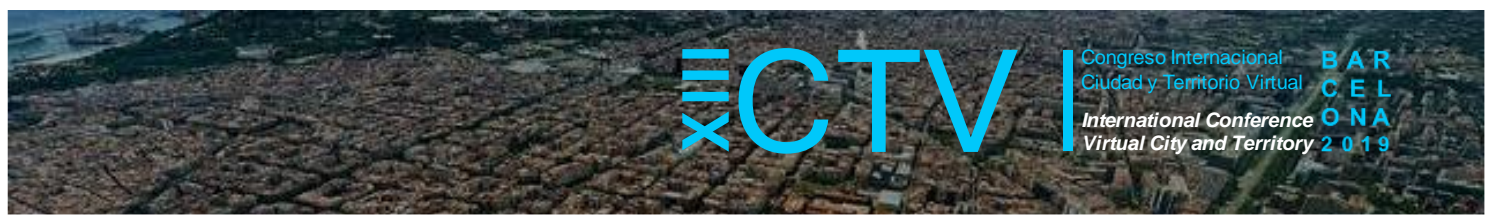

Figura 2. Evolución de la superficie y de las unidades agro-pastorales
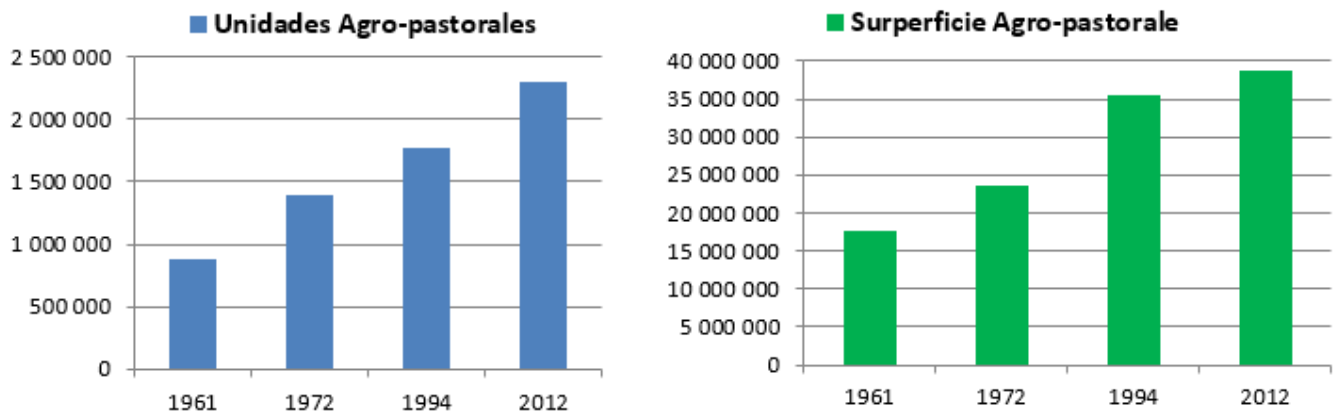

Fuente: INEI, Censos agrícolas de 1961, 1972, 1994 y 2012. [elaboración propia]

\subsection{Tipos de agricultura en el Perú}

En Perú observamos varios tipos de agricultura que tienen una relación directa con la cantidad producida y el producto cultivado. Para nuestro trabajo de investigación, será apropiado fijar estos tipos de agricultura de acuerdo con el tamaño de la unidad agro-pastoral (superficie explotada). La segmentación que utilizaremos para nuestros análisis se basará en la propuesta por Figueroa (1996). Según este autor, la agricultura peruana se diferenciaría en cuatro tipos de agricultura como se detalla en la Tabla 1.

Tabla 1. Tipos de agricultura en el Perú

\begin{tabular}{l|l|l}
\hline Tipo de agricultura & Tamaño (Ha) & Modelo de producción \\
\hline (a) Micro Agricultura (Familiar) & $:<0$ a 4,9] & Producción campesina \\
\hline (b) Pequeña agricultura (Comunal) & $:<5$ a 19,9] & Producción campesina \\
\hline (c) Mediana agricultura & $:<20$ a 49,9] & Producción capitalista \\
\hline (d) Grande agricultura & $:<50$ a más] & Producción capitalista \\
\hline
\end{tabular}

Fuente: Figueroa 1996, pp. 109. [elaboración propia]

En primer lugar (a) la Micro Agricultura (de pequeña escala o Familiar) con una superficie explotada "de menos de 5 hectáreas", en segundo lugar (b) por la Pequeña Agricultura que varía de "5 a menos de $20 \mathrm{Ha}$ ", en tercer lugar (c) por la Mediana Agricultura (realizada por cooperativas y empresas agroexportadoras) que van desde "20 a menos de $50 \mathrm{Ha}$ " y finalmente (d) por la Gran Agricultura (productores capitalistas) que incluye tierras de "50 Ha o más". Figueroa también distingue la diferencia en la producción agrícola entre dos modelos: (i) producción campesina (que corresponde a la Micro agricultura y a la Pequeña Agricultura) y (ii) producción capitalista (que corresponde a la Mediana y Gran Agricultura).

\subsection{La agricultura de la costa peruana}

La agricultura de la región natural de costa peruana tiene las siguientes características:

- Tiene altos rendimientos en la producción debido a la peculiaridad de sus tierras de origen aluvial, ricas en nutrientes, con la presencia de grandes proyectos de irrigación en la mayoría de los valles costeños. Para el valle de lca el riego de agua subterránea representa el 50\% de la dotación de agua para la agricultura. (Muñoz, I. 2011 pp. 279).

- Tiene la gestión técnica, característica de los medianos y grandes dominios agrícolas, aplicando por ejemplo técnicas agrícolas de irrigación y de fertilidad del suelo. Así como 


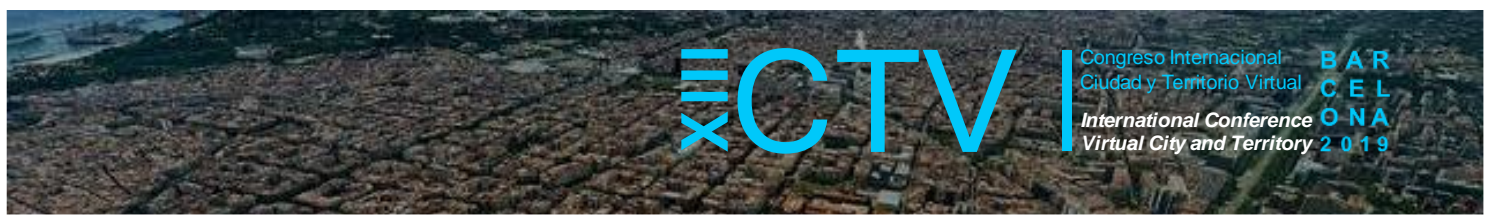

métodos nocivos para el medio ambiente, uso de pesticidas e insecticidas vinculados a la agroindustria. (Figueroa, A. 1996 pp. 156).

- Tiene cultivos agro-industriales como la caña de azúcar, el algodón, hortalizas y frutas, que son productos altamente rentables. Además, la agricultura de esta región es mayoritariamente mecanizada, con recursos financieros o crédito adecuado.

Por su localización la costa tiene fácil acceso al comercio exterior, como se ve en la figura 2.

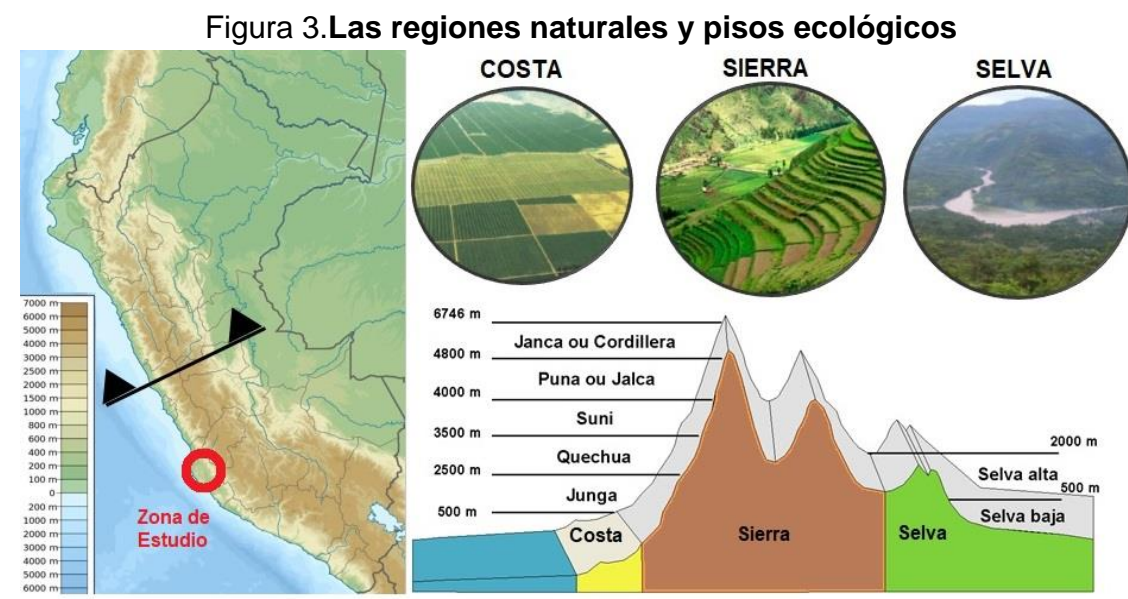

Fuente: Pulgar, J. 1938. Las ocho regiones naturales del Perú. [elaboración propia]

\subsection{Evolución de la población urbana y rural del Valle de Ica}

En la Figura 4 se observa que la población urbana del valle ha tenido un incremento positivo y sostenido del $3 \%$ por año. De manera contraria se constata el decrecimiento de la población rural desde el año 1981 pasando de 38,3 mil habitantes a 26,1 mil habitantes en el 2012.

Figura 4. Evolución de la población urbana y rural del Valle de Ica

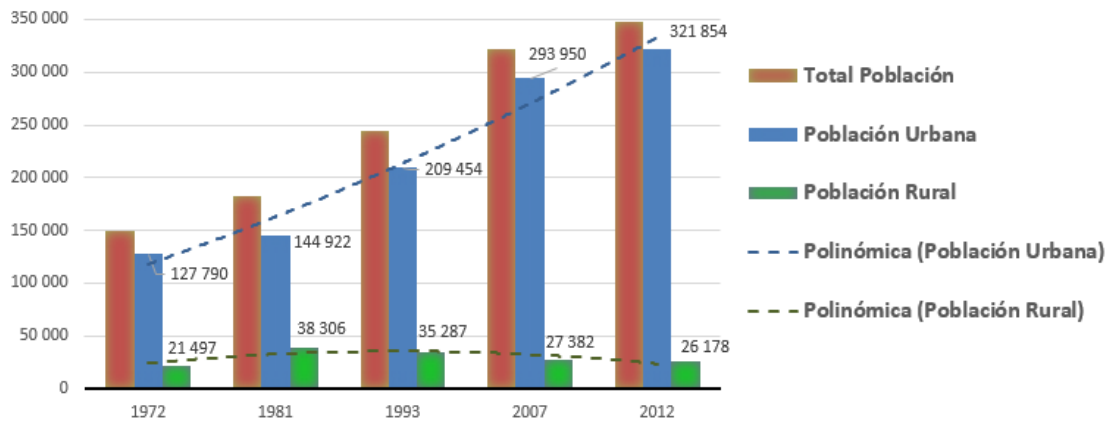

Fuente: INEI, Censos de población 1972, 1981, 1993, 2007 y 2012. [elaboración propia]

La incorporación de nuevas tierras eriazas, como tierras agrícolas y no agrícolas (de pastoreo), así como el incremento de capital en la compra y acumulación de tierras comunales como fines agrícolas, propicia una nueva dinámica de la producción agrícola en el país como en el valle de Ica, generando actualmente una nueva dinámica sobre el crecimiento de la ciudad y los asentamientos rurales cuyas dimensiones e impactos son todavía desconocidos. De ahí la importancia de este estudio, cuyo objetivo es conocer cómo se dan las actividades agrícolas, cuál es su relación con el desarrollo social, económico y medio ambiental del valle de Ica. 


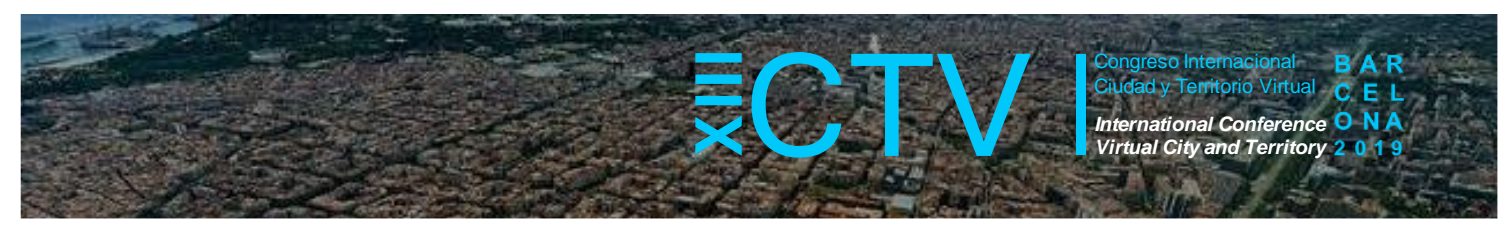

\subsection{Políticas de tierras}

En esta sección daremos una visión general de las principales políticas de tierras porque esta revisión nos ayudará a comprender la importancia de la tierra como recurso natural y cómo los diferentes gobiernos han gestionado el derecho de acceso y la propiedad de las tierras en el Perú.

\section{- La reforma agraria}

El primer intento de reforma agraria data de 1956, durante el mandato del presidente Manuel Prado (1956-62), quien creó en ese momento una Comisión para la Reforma Agraria (CRAV). Esta estaba compuesta en gran parte por propietarios de haciendas relativamente progresistas, quienes hicieron la propuesta de establecer límites a la propiedad agrícola con un máximo de 250 hectáreas. Pero fue solo en el gobierno de Juan Velasco Alvarado que se estableció el límite de propiedad de las tierras agrícolas en 150 hectáreas. (Castillo, 2011).

En junio de 1969, durante el gobierno de Juan Velasco Alvarado (1968-75), se promulgará la Ley de Reforma Agraria, el Decreto Ley 17716, que abolió el sistema de haciendas. El objetivo principal de la Reforma Agraria era democratizar las tierras agrícolas para la población rural. El proceso se llevó a cabo utilizando la ideología que decía "la tierra es para quien la trabaja", tierra que hasta esa fecha estaba en posesión de los hacendados. En ese momento, los diferentes sectores de la población urbana y rural consideraban necesaria una Reforma Agraria (Trinidad Ardiles, 2012).

Según (Eguren F., 2004) "La Reforma Agraria Peruana fue una de las más radicales en América Latina desde que expropió las haciendas, que representaron más de 8 millones de hectáreas". Sin embargo, la mayor parte de la tierra no se distribuyó a las familias como en otras reformas en América Latina, solo el 10\% de tierras asignadas, En su lugar se crearon las Cooperativas de Producción Agrícola (CAP) y las Sociedades Agrícolas de Interés Social (SAIS), entes conformados por ex trabajadores de las haciendas de la costa como de la sierra.

\section{- Fin de la reforma agraria y comienzo de la parcelación}

Después de unos años de iniciación de la Reforma Agraria dentro de las CAP y las SAIS surgieron problemas debido a la mala gestión de los nuevos propietarios, que desconocían las buenas prácticas en administración y gestión agrícola; hasta entonces estos solo se habían dedicado al trabajo manual de la tierra. Así, después de diez años de experiencias asociativas en la costa, los propios miembros de las CAP decidieron disociar las cooperativas y distribuir las tierras entre sus miembros. El resultado ha sido la proliferación de pequeñas propiedades familiares, que se han seguido subdividiendo hasta hoy. Proceso conocido como "parcelación".

Hacia el final de la Reforma Agraria hubo algunas medidas legales que significaron un primer paso atrás en términos de límites de propiedad de la tierra. Por otro lado, el interés del estado en la tierra "Eriazas", que eran susceptibles de ser irrigadas, se hizo visible. En 1982, durante el gobierno de Fernando Belaunde (1980-85), se creó el Proyecto Privado de Desarrollo Integral (PRIDI), su regulación estableció que las tierras Eriazas podrían otorgarse en concesiones con un mínimo de 100 ha y un máximo de 50 mil hectáreas. Posteriormente, en 1988 en el gobierno de Alan García (1985-90), el Decreto Supremo (DS)029-88-AG elevó los 


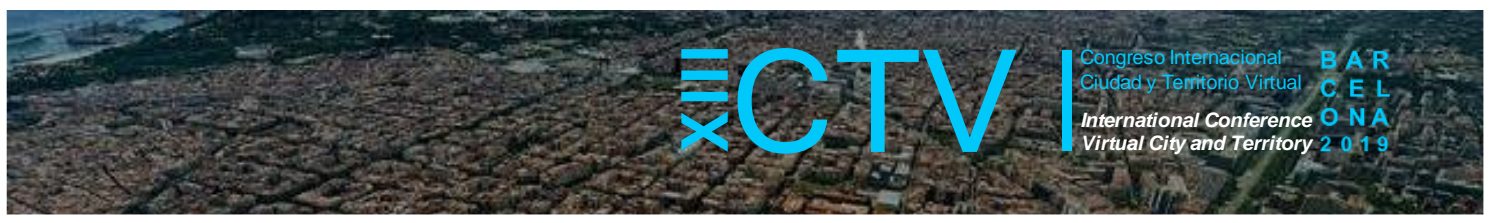

límites de la propiedad a 450 hectáreas para una extensión agrícola con riego en la costa y la selva. Estos cambios legislativos se hicieron bajo la Constitución de 1979, que prohibía el latifundio y establecía la conducta directa de la tierra como una condición indispensable para la garantía legal de propiedad. La misma que protegió la propiedad de las comunidades campesinas al declararla imprescriptible, inalienable e inembargable.

\section{- Libre acceso a la tierra}

Aunque ya ha sido evidente que los gobiernos posteriores a la de la reforma agraria buscaron la liberación del acceso a la tierra, este solo llego en el gobierno de Alberto Fujimori (19902000) donde se promulgó un paquete de leyes que finalmente liberaron el acceso a la tierra al capital privado nacional y extranjero. Esta apertura al mercado de tierras se consolidó con la nueva Constitución de 1993.

En 1995, se promulgó la Ley 26505 "Ley de inversión privada en el desarrollo de actividades económicas en la tierra del territorio nacional y las comunidades campesinas y nativas", que permite la privatización individual de las tierras de las comunidades campesinas y nativas; además ley eliminó cualquier límite de tamaño para las tierras agrícolas. En 1997, la Ley 26845 "registro de tierras de comunidades campesinas en la costa" introduce una nueva dimensión legal, la del abandono de tierras por parte de las comunidades costeras (esto permite la recuperación de tierras que no son trabajadas por el Estado)

Todos estos cambios legales han permitido no solo una nueva dinámica de tierras agrícolas sino también en la propiedad de tierras con fines extractivos, como la minería y los hidrocarburos. En los gobiernos de Alejandro Toledo (2001-2006) y Alan García (2006-2011) el contexto no ha cambiado mucho, es decir, el marco legal aún favorece la inversión privada nacional y extranjera sobre los derechos de las comunidades campesinas y nativas.

\section{Análisis evolutivo de la tierra agrícola y urbana del Valle de Ica}

\subsection{Estructura de la tierra agrícola en el valle de lca}

En el periodo de los últimos tres censos agrícolas 1972-2012, se dieron grandes cambios estructurales el sector agrícola en todo el país como en el departamento de Ica. El análisis para la provincia de Ica se realizará en los periodos inter-censales (a) 1972-1994 y (b) 1994-2012.

Tabla 2. Tipos de agricultura en el Perú.

\begin{tabular}{|c|c|c|c|c|c|c|c|}
\hline \multirow{2}{*}{ Tipo } & \multirow[b]{2}{*}{ Intervalo } & \multicolumn{2}{|c|}{1972} & \multicolumn{2}{|c|}{1994} & \multicolumn{2}{|c|}{2012} \\
\hline & & Nro.UA & Sup.Ha & Nro.UA & Sup.Ha & Nro.UA & Sup.Ha \\
\hline Micro agricultura & $<0$ a 4,9$]$ & $13^{\prime} 090$ & $44^{\prime} 638$ & $10^{\prime} 227$ & $111^{\prime} 755$ & $13^{\prime} 707$ & $11 ' 862$ \\
\hline Pequeña agricultura & $<5$ a 19,9] & 341 & 3'234 & 1'396 & 8'236 & 1'537 & $12 ' 774$ \\
\hline Mediana agricultura & $<20$ a 49,9$]$ & 83 & 2'569 & 190 & 3'249 & 299 & 7'857 \\
\hline \multirow[t]{2}{*}{ Gran agricultura } & $<50$ a más $>$ & 98 & $22 ' 287$ & 155 & $13^{\prime} 902$ & 233 & $94 ' 439$ \\
\hline & Total & $13^{\prime} 612$ & $32 ' 728$ & 11 '968 & $37^{\prime} 142$ & $15^{\prime} 776$ & $126 ' 933$ \\
\hline
\end{tabular}

Fuente: INEI, IV censo agrícola 1972,1994 y 2012. [elaboración propia] 
Figura 5. Número y Superficie de las propiedades en el Valle de Ica

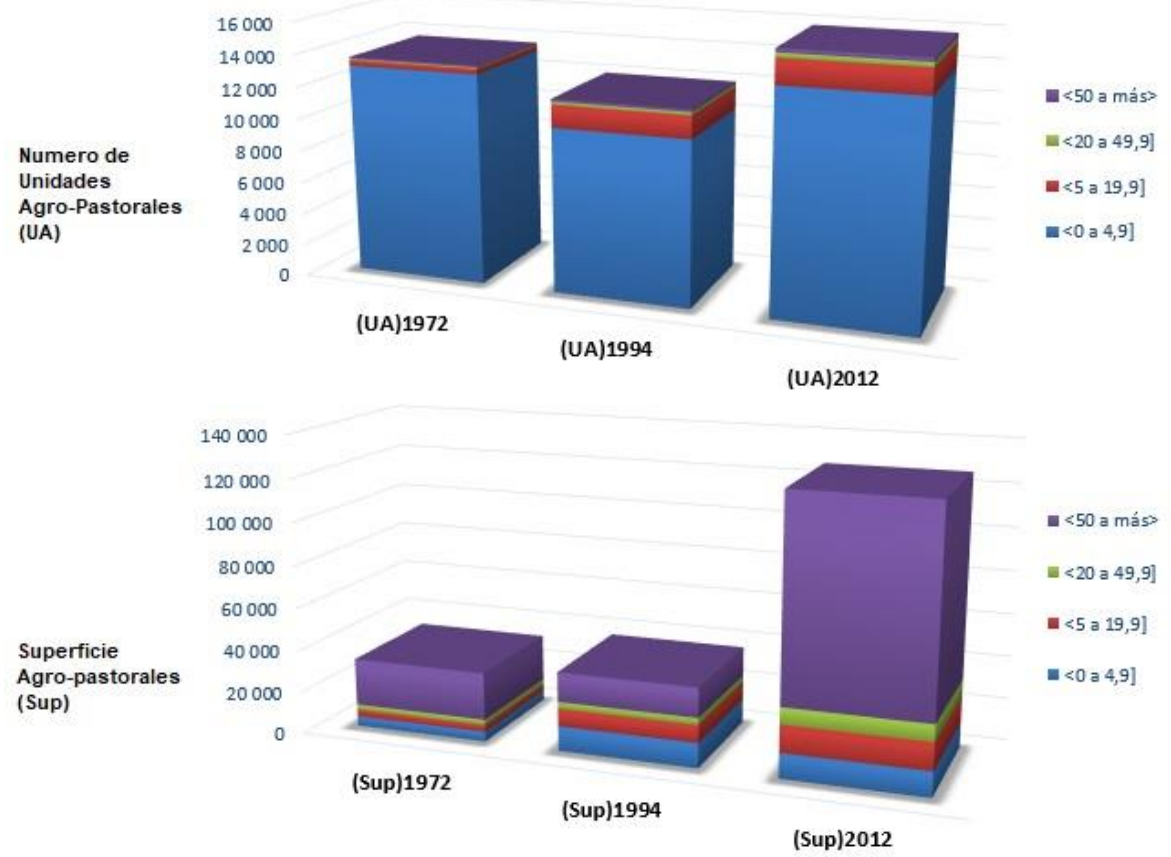

Fuente: INEI, IV censo agrícola 1972,1994 y 2012. [elaboración propia]

\section{- Período inter-censal 1972-1994}

En 1972 el segmento de la "Gran Agricultura" constaba de 98 UA que representaba solo el $0.7 \%$ del total de UA y explotaba 22,3 mil hectáreas lo que representaba el $68 \%$ del total de la superficie agrícola del valle. $Y$ en 1994, en el mismo segmento constaba de 155 UA que representaba el $1.3 \%$ del total de UA y explotaba 13,9 mil hectáreas lo que representaba el $37.4 \%$ del total de la superficie agrícola del valle.

En 1972, en cuanto del segmento de la "Micro Agricultura" constaba de 13'090 UA que representaba el 96,2\% del total de UA y explotaba solo 4'638 hectáreas lo que representaba el $14,2 \%$ del total de la superficie agrícola del valle. Y en 1994, en el mismo segmento constaba de $10^{\prime} 227$ UA que representaba el $85,5 \%$ del total de UA y explotaba 11'755 hectáreas lo que representaba el $31,6 \%$ del total de la superficie agrícola del valle.

Como resumen en este período se caracteriza por la democratización de las tierras agrícolas se constata que el segmento de la "Gran Agricultura" tuvo un decrecimiento de su superficie bajo su dominio, y ello como resultado de las políticas que se implementaron al principio y durante la Reforma Agrícola, para pasar luego por el periodo de crisis del final de la Reforma Agraria.

\section{- Período inter-censal 1994-2012}

En este periodo el segmento de la "Gran Agricultura" paso de tener 155 a 233 UA y de explotar 13'902 hectáreas a 94'439 hectáreas lo que representaba un incremento del 579\% de hectáreas bajo su dominio. 


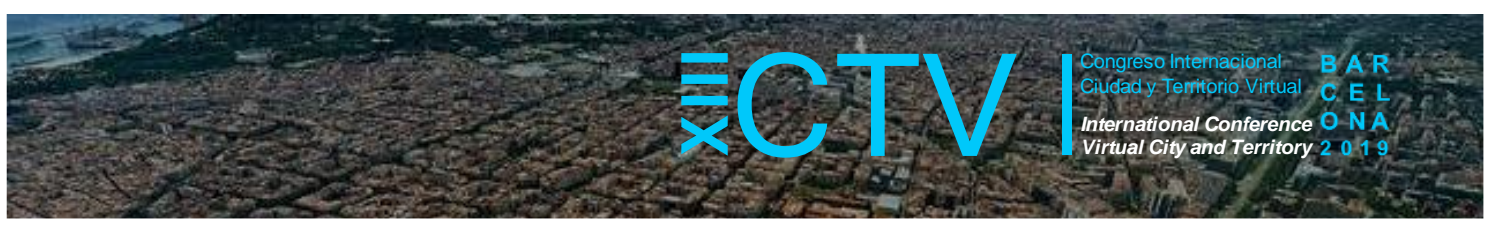

En este periodo el segmento de la "Micro Agricultura" paso de tener 10'227 a 13'707 UA y de explotar 11'755 hectáreas a 11'862 hectáreas lo que representaba un incremento del 1\% de hectáreas bajo su dominio.

Como resumen en este período se caracteriza por la concentración de las tierras agrícolas por parte del segmento de la "Gran Agricultura" segmento que incremento su dominio agrícola en $571 \%$. En el caso del segmento de "Micro Agricultura" se constata un incremento mínimo del $1 \%$ de hectáreas bajo su dominio.

En general podemos decir que nuevo contexto legal ha facilitado y alentado, las compras de nuevas tierras comunales y estatales. En el caso del Valle de Ica, estas adquisiciones permitirían la explotación de nuevas tierras "Eriazas", tierras que podrían ser irrigables, lo que representa un problema ambiental de sobreexplotación del agua del subsuelo.

\subsection{Evolución de la producción agrícola y El boom agro-exportador peruano}

La evolución de la producción agrícola, en el período de 1972-2012, tuvo dos períodos, (1) el período anterior a la década de 1990 y (2) el período desde la década de 1990 hasta la actualidad. El primer período se observa que la producción agrícola se mantuvo más o menos estable, apoyada por la inversión pública de los diferentes gobiernos. Durante el segundo período se observa una gran producción agrícola y cambio de cultivos tradicionales por los emergente. Debido como ya se mencionó a varios factores como el nuevo marco jurídico favorable a las actividades agrícolas, y el acceso a la tierra, la integración de Perú en el mercado mundial, a través de acuerdos comerciales, así como la inversión privada del "gran capital" en la producción agroindustrial y de exportación.

\section{- Evolución de los cultivos agrícolas tradicionales y emergentes}

A partir de la década de los años 90 se hace evidente el cambio de preferencia de los cultivos tradicionales por los emergentes, evolución que se aprecia en la Figura 6.

\section{Figura 6. Las exportaciones nacionales, en cultivos tradicionales y emergentes}

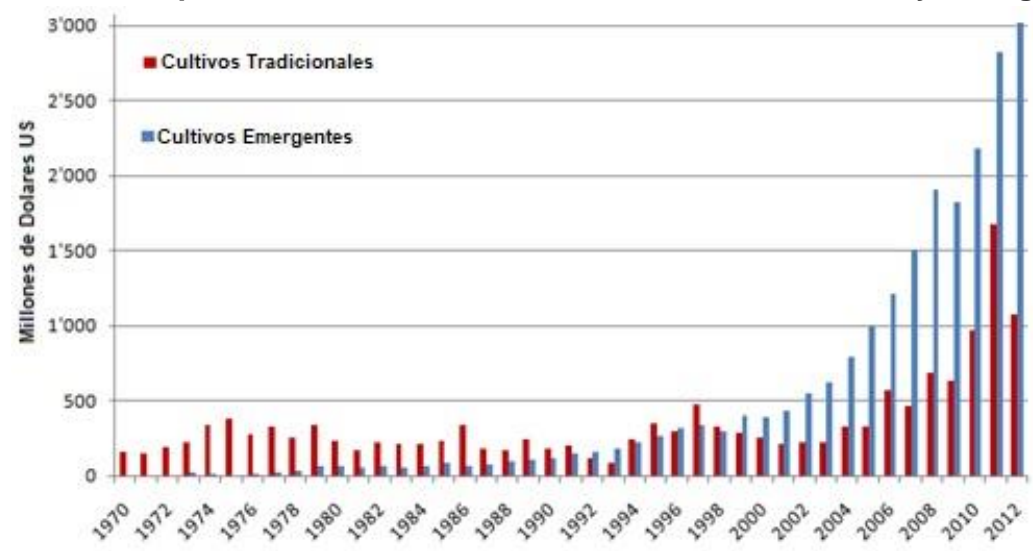

Fuente: MINAG $^{4}$, BCRP ${ }^{5}$ y SUNAT ${ }^{6}$. [Elaboración propia]

\footnotetext{
${ }^{4}$ MINAG, Ministerio de Agricultura

${ }^{5}$ BCRP, Banco Central de Reserva del Perú.
} 


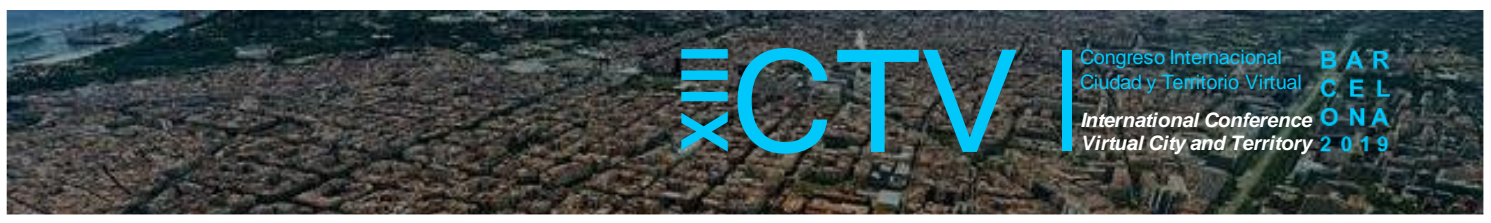

\section{- Superficie y producción de los cultivos tradicionales y emergentes}

En el Valle de Ica del periodo de 1990 al 2012 se constata la caída en la producción de algodón, pasando de 20 mil hectáreas a 3 mil hectáreas, decreciendo al $15 \%$. Y un crecimiento en hectáreas de la producción de cultivos emergentes, como por ejemplo los espárragos que el mismo periodo paso de poco menos de mil hectáreas a las 12 mil hectáreas cultivadas, lo que lo ubica en el principal cultivo y producto de exportación como se aprecia en la Figura 7.

Figura 7. Superficie y producción, principales cultivos Valle de Ica

a) Superficie de cultivos principales ( $\mathrm{Ha}$

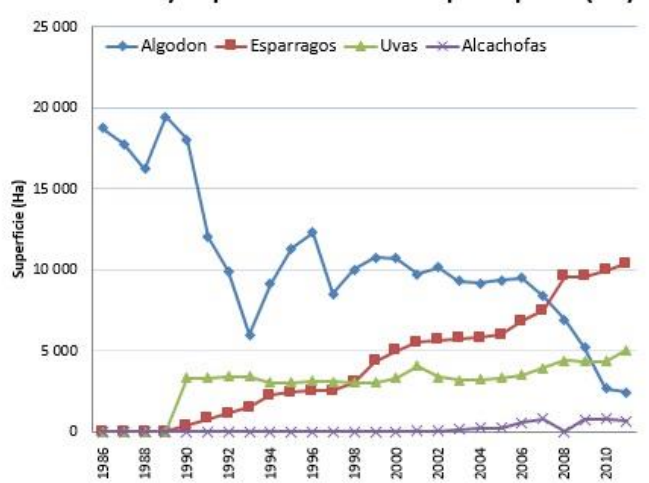

b) Produccion de cultivos principales (TM)

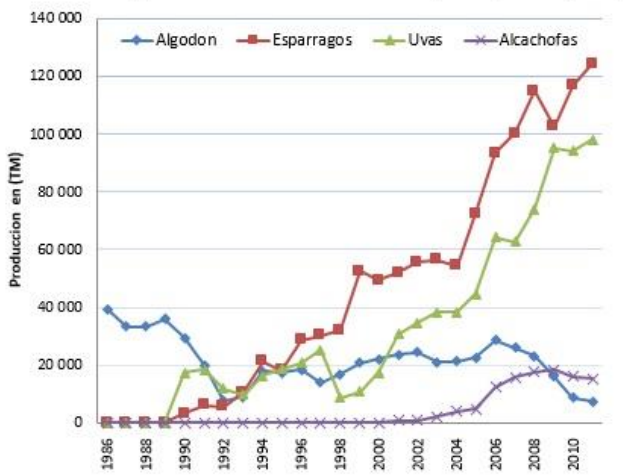

Fuente: MINAG, BCRP y SUNAT. [Elaboración propia]

\subsection{Imágenes satélites para determinar la extensión agrícola y urbana}

Para corroborar el verdadero crecimiento de la extensión agrícola, así como la urbana en la zona de estudio, período comprendido entre los años de estudio. Se realiza el análisis espacial con ayuda de imágenes satélite tomadas en 1990.04.23 y 2010.05.10 (LANDSAT 6 y 7). Para nuestra zona de estudio, "Valle de Ica Perú", estas imágenes satelitales están suficientemente espaciadas en el tiempo como para comparar los resultados estadísticos con los espaciales sobre el territorio en cuestión.

Los instrumentos de medición utilizados para la adquisición de información de teledetección para el año 1990 y para el año 2010 son, respectivamente, el multi-espectral TM y el instrumento ETM +. Para este estudio, se utilizaron todos los canales $(1,2,3,4,5$ y 7$)$ excepto el canal 6. Todas estas imágenes satelitales tienen una resolución de $30 \mathrm{~m}$. Estos canales fueron elegidos por su capacidad de discriminar entre diferentes usos de la tierra, es decir, diferenciar entre plantas, suelo, agua y el suelo urbano. Siendo las características de los canales los siguientes (Universidad de Ginebra, 2012), El Canal 1: permite la distinción suelovegetación, el canal 2: permite diferenciar el estado de salud de las plantas, el canal 3: distinción de tipo de vegetación, el canal 4: permite ver la evolución de la biomasa, el canal 5: también permite la distinción de la vegetación y la humedad del suelo, y el canal 7: distingue tipos de suelos y rocas.

Para llevar a cabo el análisis de la extensión de la frontera agrícola, comenzamos por obtener dos imágenes, índices de vegetación, para los años de estudio 1990-2010. Los canales 3 y 4 se utilizan para calcular el índice de vegetación «NDVI», la combinación de estos últimos

\footnotetext{
${ }^{6}$ SUNAT, Superintendencia Nacional de Administración Tributaria
} 


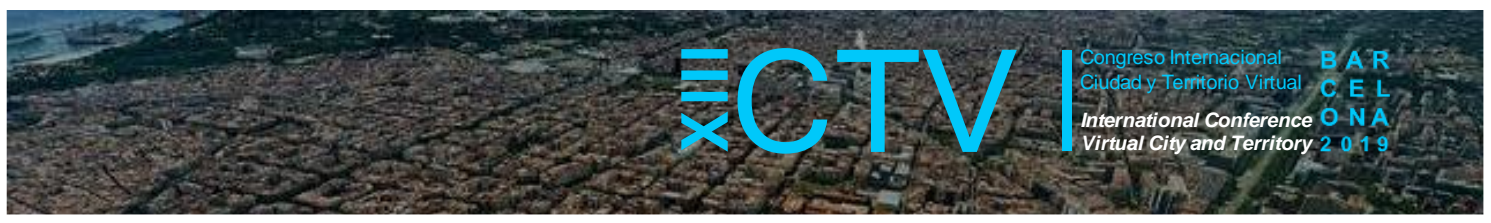

canales permite la adquisición de 3 índices «Tasseled cap» (brillo, verde y humedad) y finalmente la composición de estos últimos neo-canales nos da una imagen resultado, que nos muestra la distinción de la vegetación de otros elementos del suelo. En la Imagen resultado se aprecia una gran presencia de plantas, para ser más precisos es la presencia de diferentes cultivos. Cuanto más claras son las áreas, más intensa es la actividad de la clorofila, es decir de las plantas, como se aprecia en la Figura 8a.

Luego, para distinguir entre los diferentes usos del suelo en el Valle de Ica. Decidimos analizar la composición de los canales 2, 3 y 4. Esta composición nos permite distinguir entre el suelo y la vegetación. El tipo de vegetación y la evolución de la biomasa se muestra en diferentes tonos de rojo. Finalmente, sobre estas imágenes, composición 234, procedimos a digitalizar la superficie agrícola y urbana, así como otros elementos lo suficientemente importantes para este análisis. Y todo esto con el objetivo de estimar la nueva superficie agrícola que se ganó en el periodo analizado 1990-2010.

Figura 8.Evolución de la superficie agrícola y urbana a escala 1/500000.

a) Indice de vegetación (NDVI) 1990-2010

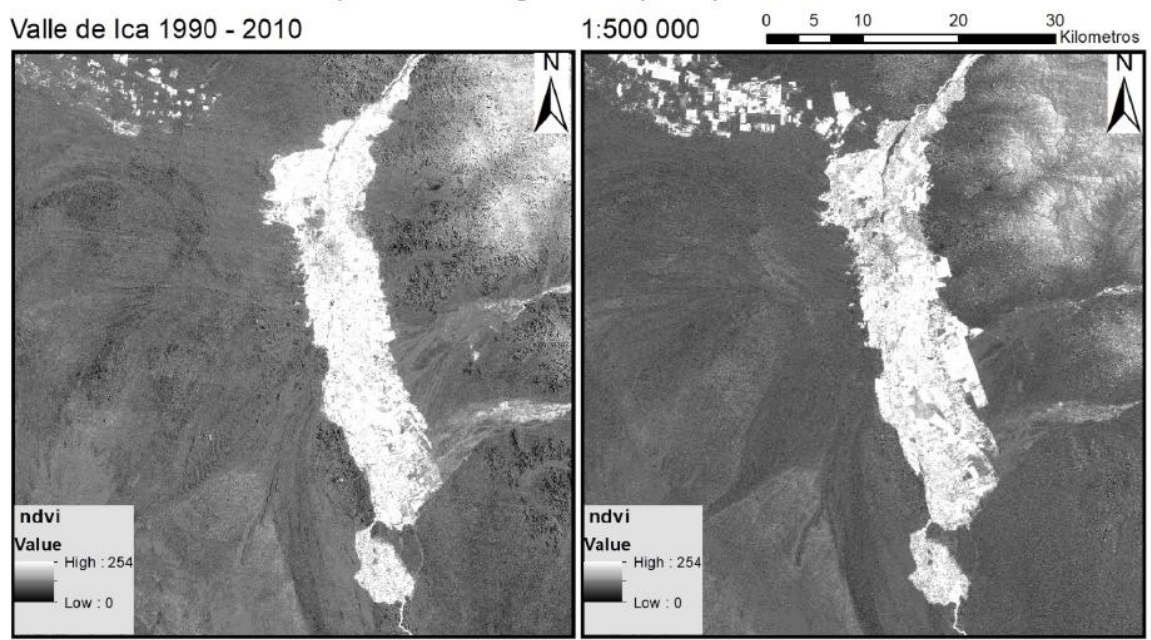

b) composicion234, distincion suelo-vegetacion, 1990-2010
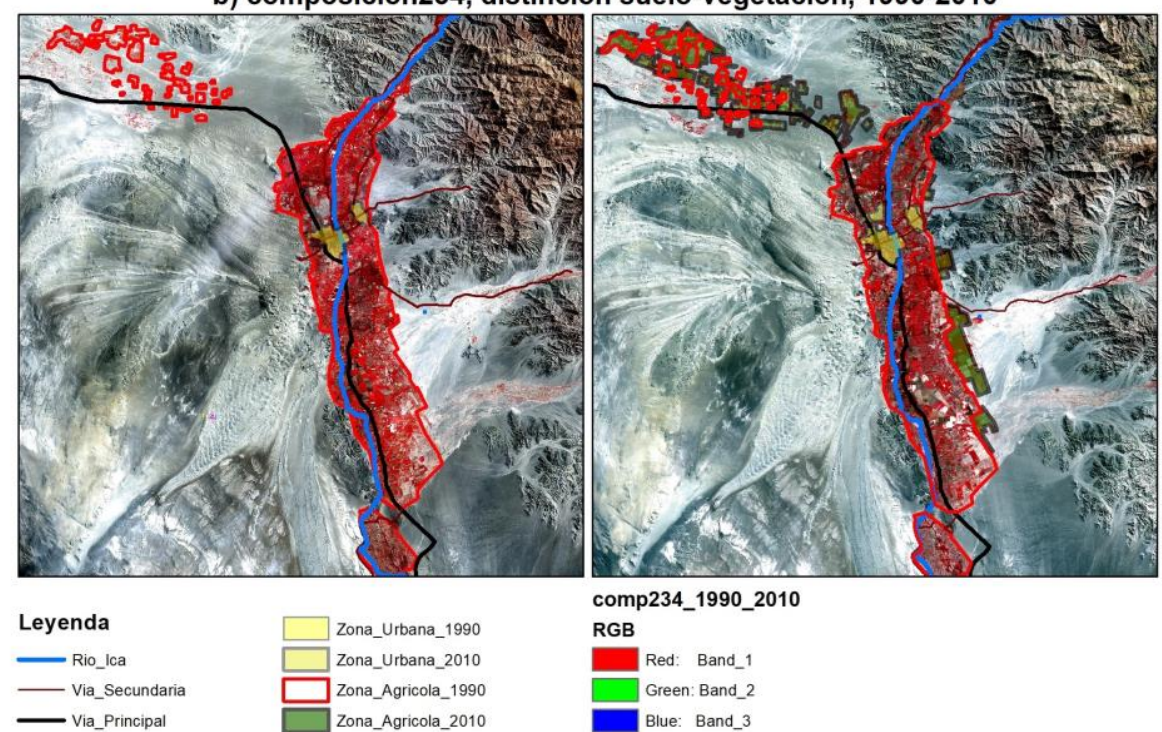

comp234_1990_2010

RGB

Red: Band_1

Green: Band_2

Fuente: Los datos utilizados han sido descargados del sitio web: http://glcfapp.glcf.umd.edu. [Elaboración propia]. 


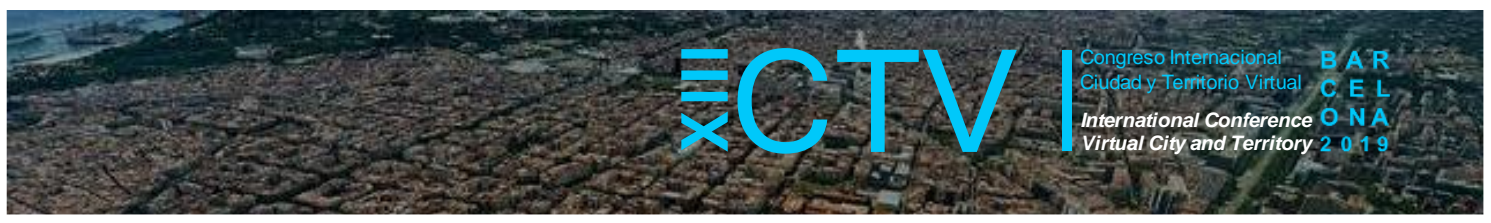

Para determinar el verdadero incremento o contracción de la frontera agrícola y urbana, se realizó una comparación entre los años de 1990-2010 en dos zonas aumentadas a una escala de 1/250000 de muestra como se aprecia en las Figura 9. En las dos zonas seleccionadas, se constata que hay un crecimiento significativo de la frontera agrícola en el Valle de Ica, en las cartas son las zonas verdes con el contorno negro llamadas Zona_Agricola_2010.

Figura 9. Evolución de la superficie agrícola y urbana aumentadas a escala 1/250000
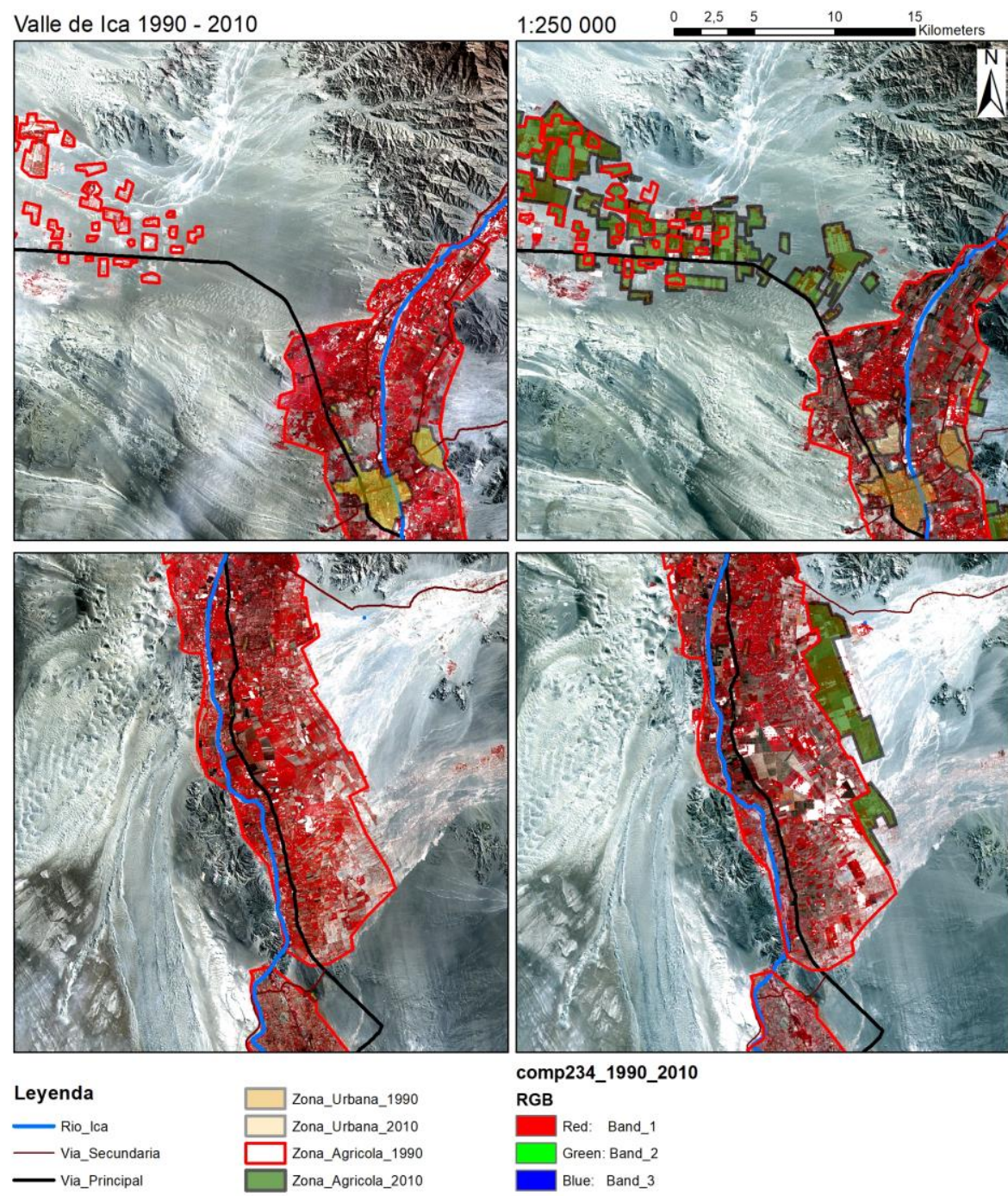

Fuente: Los datos utilizados han sido descargados del sitio web: http://glcfapp.glcf.umd.edu. [Elaboración propia].

Para conocer la extensión urbana en los mismos años de estudio, fue necesario ampliar la carta a una escala de 1/100000. A partir de estas imágenes, Figura 10, se puede constatar que el área urbana también se extendió, pero en relación con el crecimiento del área agrícola es poco significativa, como resultado de la comparación gráfica de estas dos muestras. Y según los cálculos efectuados con ayuda de software utilizado haciende aproximadamente a las 15 mil hectáreas, sim embargo este resultado es inferior a las 80 mil hectáreas según los cálculos estadísticos obtenidos según los resultados del censo agrícola del 2012. 


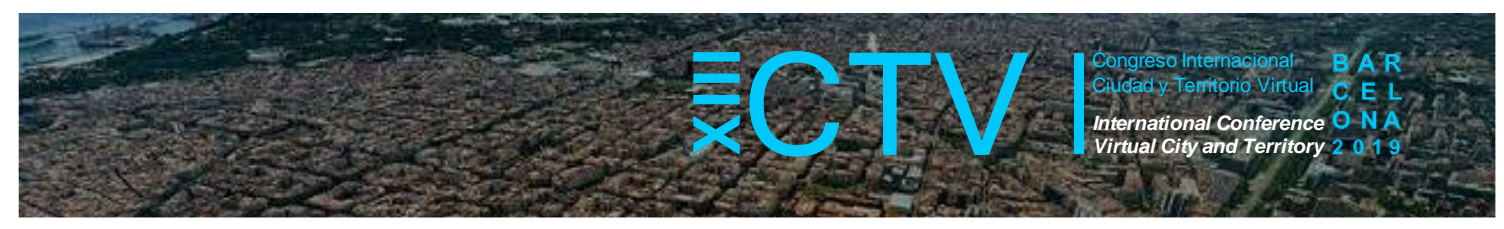

Figura 10. Evolución de la superficie agrícola y urbana aumentadas a escala 1/100000
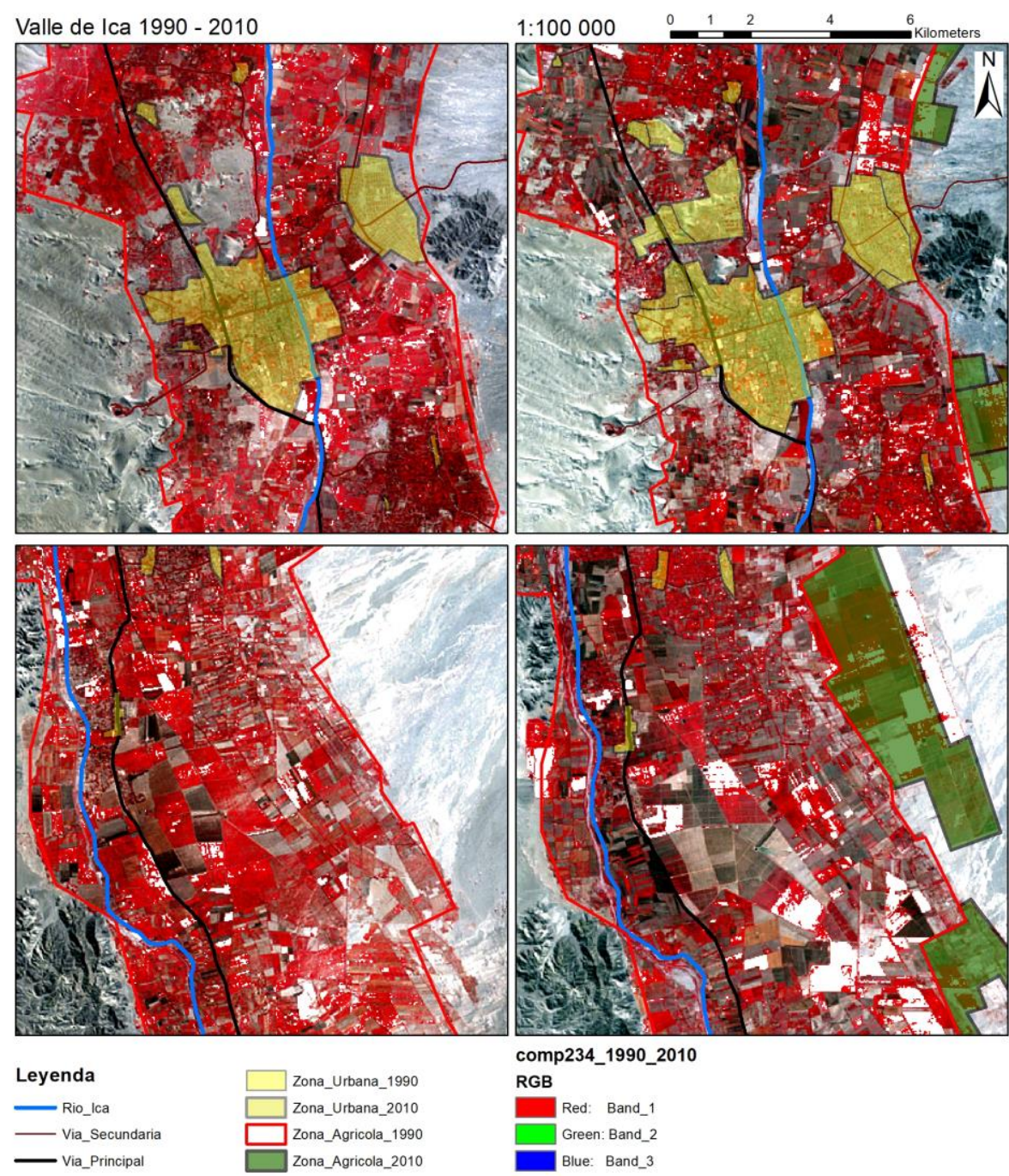

comp234_1990_2010

RGB

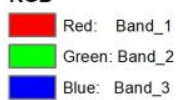

Fuente: Los datos utilizados han sido descargados del sitio web: http://glcfapp.glcf.umd.edu. [Elaboración propia].

\section{Conclusiones}

Efectivamente en el Perú se experimenta una gran dinámica sobre el mercado de la tierra, en los últimos treinta años, como consecuencia directa del nuevo marco jurídico legal de acceso a la propiedad de tierras, como de las nuevas políticas económicas del país. Políticas claramente orientadas a la liberalización de los mercados y la promoción de la inversión privada. Y el Boom agro-exportador peruano actual en consecuencia tendría su origen en el cambio de las leyes que regulan la propiedad de la tierra.

Fue durante el gobierno de Alberto Fujimori (1990-2000) que tuvo lugar la importante liberalización económica y política del país. Promulgada la "Ley de inversión privada en el desarrollo de actividades económicas en las tierras del territorio nacional y las comunidades campesinas y nativas", esta ley elimino cualquier límite de tamaño para las tierras con fines agrícolas, también permite la privatización individual de la tierra comunidades campesinas y 


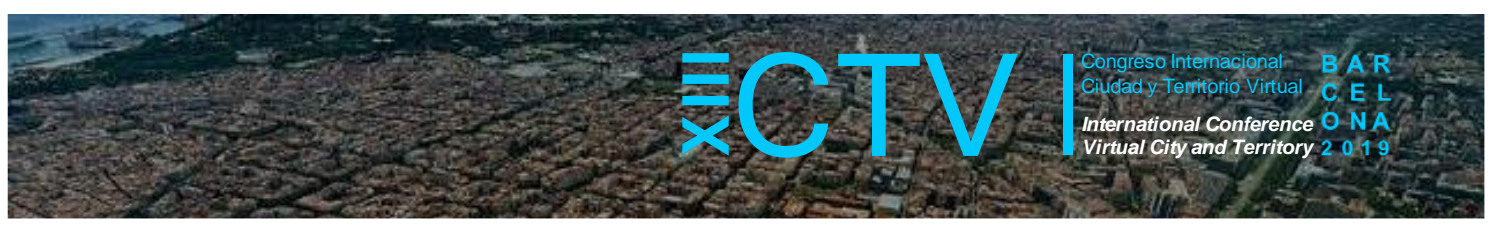

nativas. Todos estos cambios legales han permitido no solo la concentración de tierras con fines agrícolas, sino también la concentración de tierras con otros fines como los extractivos, como la minería y los hidrocarburos, así como la concentración de tierras con fines urbanos.

Las actividades predominantes en el territorio del valle de Ica predeterminan y configuran los nuevos asentamientos urbanos, su aparición sin una planificación representarían futuros problemas urbanos como la edificación informal, el crecimiento precario sin servicios básicos, etc., Es claro que en el País las nuevas poblaciones se asientan comúnmente en zonas más económicas en la periferia de las ciudades o zonas de alto riesgo y en el valle de lca es lo que ocurre pero siempre ligado a las nuevas zonas de actividades agro-industriales.

En lo que respecta a la determinación de la extensión agrícola como urbana, se puede concluir que con imágenes satelitales usadas si fue posible tener una visión general de la extensión del área agrícola y urbana permitiendo el análisis espacial territorial cuyo resultado confirmo gráficamente el incremento de la extensión agrícola en el valle, el análisis permitiendo la identificación de diferentes características del suelo, y por supuesto en nuestro caso se logra identificar claramente la extensión del área agrícola y el suelo urbano, pero también evidencia que el crecimiento físico solo fue de cerca de 15 mil hectáreas en el periodo de estudio, el cual no guarda relación con el crecimiento declarado en las cifras del último censo agrícola que fue de alrededor de 80 mil hectáreas. Al respecto podemos suponer que fue la falta del recurso agua lo que limita que dicho crecimiento sea efectivo.

Finalmente, este trabajo de investigación abre el camino al estudio de la concentración de recursos tan preciados como las tierras y el agua. Estudios que deben contar con el enfoque del desarrollo sostenible (el cual tiene presente las dimensiones de medio ambiente, economía y sociedad).

En lo que corresponde a la dimensión del medio ambiente podemos inferir que la concentración de la tierra en el valle de Ica de parte de los grandes productores tiene un impacto negativo en el territorio y sus habitantes, y esto se debería principalmente a los métodos de producción no respetuosos con el medio natural, a la sobreexplotación de aguas subterráneas, a la degradación y contaminación del suelo debido al uso intensivo de productos químicos como pesticidas. Por lo tanto, estos impactos sobre el medio ambiente son atribuibles a la nueva dinámica de tierras agrícolas y al boom agroexportador del valle.

Agradecimientos: A todas las personas que gentilmente aceptaron ser entrevistadas en especial a Trinidad Ardiles quien nos ayudó a comprender la actual problemática del sector agrícola, a Lillian Garay y a Karolina Romero por su apoyo fundamental en esta publicación, a las instituciones académicas que nos brindan la infraestructura necesaria para llevar a cabo nuestras investigaciones, a la Universidad Continental y la Universidad Nacional de Ingeniería.

Contribuciones de los autores: El primer autor ha desarrollado la revisión de las políticas de la propiedad de la tierra, el segundo autor ha realizado el análisis de la extensión agrícola y urbana usando los datos estadísticos de los últimos censos disponibles, el tercer autor ha realizado el análisis espacial con ayuda de imágenes satélites. El resto de esta publicación ha sido tratado por los tres autores. 


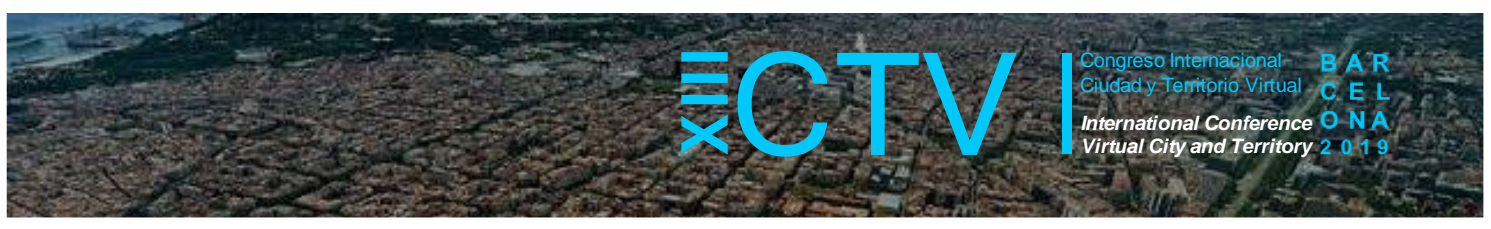

\section{Bibliografía}

Castillo, P. (2011). Serie marcos legales de acceso a la tierra: Estudio Perú. International Land Coalition, $n^{\circ} 3$ - América Latina. Recuperado de http://americalatina.landcoalition.org/node/2401

De la Vega, G. (1960). Comentarios reales de los Incas. Editorial Universo.

Decreto Ley 17716 06/1969, de 24 junio, Nueva Reforma Agraria. Recuperado de https://www.ecolex.org/es/details/legislation/decreto-ley-no-17716-ley-de-reforma-agraria-lexfaoc124295/

Eguren, F. (2004). Las políticas agrarias en la última década: una evaluación Lima - Perú: Seminario permanente de investigación agraria (SEPIA) Perú: el problema agrario en debate.

Eguren, F. (2003). La Agricultura de La Costa Peruana. Lima - Perú: Debate Agrario, 1-37.

Eguren, F. (1989). Los nuevos grupos dominantes en la agricultura peruana. Lima - Perú. Debate Agrario, 11-32.

Figueroa, A. (1996). Pequeña agricultura y agroindustrial en el Perú. Lima-Perú. Economía, XIX, 93-170.

Ley 26505 7/1995, de 14 de julio, Ley de inversión privada en el desarrollo de actividades económicas en la tierra del territorio nacional y las comunidades campesinas y nativas. Recuperado de https://www.agropuno.gob.pe/files/documentos/normatividad/ley/Ley 26505.pdf

Ley $N^{\circ} 26845$ 7/1997, de 9 de julio, Ley de Titulación de las Tierras de las Comunidades Campesinas de la Costa. Recuperado de https://centroderecursos.cultura.pe/sites/default/files/rb/pdf/Ley\%20de\%20titulacion\%20de\%20ti erras\%20campesinas\%20de\%20la\%20costa.pdf

Muñoz, I. (2011). Desigualdades en la distribución del agua de riego. El caso del valle de Ica. Perspectiva. (pp. 103 - 117).

Murra, J. (1978). «La organización económica del Estado Inca». Siglo XXI.

Poma de Ayala, G. (1936). «Nueva crónica y buen Gobierno». Lima: Fondo de Cultura.

Pulgar, J. 1938. Las ocho regiones naturales del Perú.

Trinidad Ardiles, R. (2012, marzo 08). Entrevista: la agricultura y la problemática de la concentración de tierras en el Perú. (J. Poma, entrevistador) Lima, Perú.

Universidad de Ginebra. (2012) IDRISI - Rehaussements radiométriques: certificat complementaire en geomatique. Recuperado de https://moodle.unige.ch/course/view.php?id=1712 